\title{
EDITORIAL
}

\section{Critical synopsis and key questions in brain death determination}

\author{
Eelco F. M. Wijdicks ${ }^{*}$ \\ (c) 2019 Springer-Verlag GmbH Germany, part of Springer Nature
}

\begin{abstract}
Introduction
This thematic issue in Intensive Care Medicine subscribes to a fundamental medical principle: Brain death is death, and organ and tissue donation must be a priority. For all involved in declaring brain death, there is acceptance, resignation, compassion, support, and a deep humanistic appreciation that lives can be saved. Intensivists (with their respective academies and societies) have defined the practice, proposed clinical pathways, and introduced safeguards. After much reflection in the 1960s-1980s, brain death determination has been medically settled for most nations worldwide.

The Harvard Criteria for Brain Death-legendary and lauded-are now outdated [1]. Guidelines from the American Academy of Neurology released in 1995 and 2010 have precisely defined irrevocable brain and brainstem damage, and the adult criteria have worked exceptionally well [2]. Worldwide variations on a common theme exist but with the worthy intention of preventing mistakes. Intensivists, and often neurointensivists and neurosurgeons, have developed expertise through apprenticeship. We can examine this practice more closely periodically by posing key questions.
\end{abstract}

\section{Who does it?}

It's a simple calculus. We know catastrophic brain injury rarely leads to loss of all brainstem function. The intensivist in a busy trauma unit or neurosciences intensive care unit may perform a brain death examination once or twice a month (at the most), but most of us do it only occasionally. So this "expertise" is often not really expertise (if you compare it with endotracheal intubation or central line placement), and even more problematic, the number of brain

*Correspondence: wijde@mayo.edu

Division of Neurocritical Care and Hospital Neurology, Mayo Clinic, 200

First Street SW, Rochester, MN 55905, USA death determinations has decreased significantly over the years. We do not know why; cases may be missed or care withdrawn too quickly in hopeless situations [3]. When seeing these patients, we should not forget that hopeless cases can create hope for those patients on a waiting list.

Most agree that neurologists and neurosurgeons are best qualified to do a comprehensive evaluation and assess neurologic ambiguities. However, there are no proven metrics for judging proficiency; without these, any certificate will be meaningless. Outside the USA, the laws in many EU countries dictate special specialist requirements for brain death determination. This is not necessarily the same as being qualified. For now, in order to reduce critical errors, hospitals should define competence. It is a plea for earned practice.

\section{How to do it?}

Brain death is the absence of cortical and brainstem function in an apneic patient receiving circulatory support with a massive structural hemispheric and brainstem injury. Under these conditions, 25 simple tests should suffice (Fig. 1). Keep looking for a pitfall. Keep scrutinizing medication listings if you do not know the patient well. Remain skeptical. The brain death diagnosis is made through an organized, stepwise, prioritized clinical neurologic examination: (1) assessment of prerequisites, (2) neurologic examination, and (3) apnea testing. Step 1 establishes the cause of coma, confirms futility of intervention, and excludes confounders. Step 2 confirms the absence of brainstem reflexes and motor responses. Step 3 conclusively determines the absence of a respiratory drive. It is non-negotiable.

\section{When to do it?}

When you have ruled out confounders such as lingering drugs in critically ill patients and the utility of medical, neurosurgical, or other interventions (osmotic agents, ventriculostomy, craniotomy), you may be ready to

\section{实




\section{Assessments to Declare a Patient Brain Dead}

Prerequisites (ALL MUST BE CHECKED)

1. $\square$ Coma, irreversible and cause known

2. $\square$ Neuroimaging explains coma

3. $\square$ Sedative drug effect absent (if indicated, order a toxicology screen)

4. $\square$ No residual effect of paralytic drug (if indicated, use peripheral nerve stimulator)

5. $\square$ Absence of severe acid-base, electrolyte, or endocrine abnormality

6. $\square$ Normal or near normal temperature (core temperature $\geq 36^{\circ} \mathrm{C}$ )

7. $\square$ Systolic blood pressure $\geq 100 \mathrm{~mm} \mathrm{Hg}$

8. $\square$ No spontaneous respirations

Examination (ALL MUST BE CHECKED)

9. $\square$ Pupils non-reactive to bright light (typically mid-position at 5-7 $\mathrm{mm}$ )

10. $\square$ Corneal reflexes absent (use both saline jet and tissue touch)

11. $\square$ Eyes immobile, oculocephalic reflexes absent (tested only if C-spine integrity ensured)

12. $\square$ Oculovestibular reflexes absent (50 cc of ice water in each ear sequentially)

13. $\square$ No facial movement to noxious stimuli at supraorbital nerve or temporomandibular joint compression. (absent snout and rooting reflexes in neonates)

14. $\square$ Gag reflex absent (gloved index finger to posterior pharynx)

15. $\square$ Cough reflex absent to tracheal suctioning (at least 2 passes)

16. $\square$ No motor response to noxious stimuli in all 4 limbs (triple flexion response is most common spinal-mediated reflex)
Apnea Testing (ALL MUST BE CHECKED)

17. $\square$ Patient is hemodynamically stable (systolic blood pressure $\geq 100 \mathrm{~mm} \mathrm{Hg}$ )

18. $\square$ Ventilator adjusted to normocapnia $(\mathrm{PaCO}, 35-45 \mathrm{~mm} \mathrm{Hg})$

19. $\square$ Patient pre-oxygenated with $100 \%$ oxygen for 10 minutes $\left(\mathrm{PaO}_{2} \geq 200 \mathrm{~mm} \mathrm{Hg}\right)$

20. $\square$ Patient maintains oxygenation with a PEEP of $5 \mathrm{~cm} \mathrm{H}_{2} \mathrm{O}$ (if not, consider recruitment maneuver )

21. $\square$ Disconnect ventilator

22. $\square$ Provide oxygen via an insufflation catheter to the level of the carina at 6 liters/min or attach T-piece with CPAP valve @ 10-20 $\mathrm{cm} \mathrm{H}_{2} \mathrm{O}$ and resuscitation bag

23. $\square$ Spontaneous respirations absent

24. $\square$ Arterial blood gas drawn at 8-10 minutes, patient reconnected to ventilator

25. $\square \mathrm{PaCO}_{2} \geq 60 \mathrm{~mm} \mathrm{Hg}$, or $20 \mathrm{~mm} \mathrm{Hg}$ rise from normal baseline value or Apnea test aborted and confirmatory ancillary test (EEG or cerebral blood flow study)

Documentation

- Time of death (use time of final blood gas result or use time of completion of ancillary test)

Fig. 1 Summary of steps in neurologic evaluation of a comatose patient with a destructive acute brain injury in order to determine brain death (adapted from Wijdicks EFM Brain Death 3ed Oxford University Press, 2017)

proceed. In other words, handle with care, but prolonged observation before brain death determination is not justified if the key findings are established.

\section{Where to do it?}

The intensive care unit is the most suitable venue. The emergency department is not typically equipped for a full examination, and a quick assessment of brain death is poor practice. Time is required to clarify the history and meet all prerequisites. Furthermore, the family may need some time to accept the fact that the injury is irrevocable.

\section{Who is there?}

Typically, a large staff attends the actual brain death assessment. One physician should manage the brain death checklist and mention each test before checking it 
off. The attending neurointensivist then should explain and demonstrate the examination. Our experience with family in attendance is mixed, and we have not determined if their presence at the examination intensifies emotional strain or brings better closure. Prospective studies found no positive impact on authorization for organ donation [4].

\section{What can go wrong?}

Targeted temperature management in a patient with an infusion of fentanyl or midazolam - certainly both-will seriously confound neurological examination. There is no precise way to calibrate the effect of confounders, particularly because metabolic effects persist after rewarming, especially for drugs with long half-lives.

\section{When is it more difficult?}

Two situations come to mind, both with the apnea test. Pulmonary edema with hypoxemia will rule out a traditional apnea test; recruitment and CPAP valve may be needed. Sometimes these sympathetic overdrive-induced abnormalities resolve within a day and improve the conditions for an apnea test. The apnea test also is risky in patients in an early unstable hemodynamic condition from polytrauma, but it is safe in many other clinical scenarios [5]. The second situation is ECMO, which is often used after cardiopulmonary resuscitation [6, 7]. Apnea tests in ECMO patients are not always done (or done reluctantly), but it is a deceptively simple test. The blending of carbon dioxide $\left(\mathrm{CO}_{2}\right)$ into the gas phase of an extracorporeal oxygenator has a long proven history of being safe practice. We titrate $100 \% \mathrm{CO}_{2}$ at an $8 \%$ sweep volume ratio. A sweep gas of $6 \% \mathrm{CO}_{2}$ volume produces a $\mathrm{CO}_{2}$ around $45-50 \mathrm{mmHg}$. Likewise, an $8 \%$ volume of $\mathrm{CO}_{2}$ produces a $\mathrm{pCO}_{2}$ of $65-70 \mathrm{mmHg}$ and a $10 \%$ volume of $\mathrm{CO}_{2}$ (as used in $\mathrm{pH}$-stat management) produces a $\mathrm{CO}_{2}$ of $85-90$ Lowering sweep gas to the lowest possible could lower the oxygen level and is strongly discouraged. We maintain a $\mathrm{DO}_{2}$ above 270 if renal donation is anticipated.

\section{What to tell?}

The announcement of brain death should not come as a surprise to the family, and with ongoing contact, they should become aware of the patient's prognosis following a catastrophic brain injury. In our experience, families already know their loved one is not there anymore. Brain death examinations should be undertaken under near certainty that the patient is brain dead (see prerequisites) to avoid further confusing the family when the patient turns out not to be dead. We will anticipate the family will be told that the patient has died but remains supported by artificial means. Recent interviews with families have revealed an overall good understanding of brain death and positive feelings about organ donation, which, for many, mitigates bereavement [8].

\section{What next?}

In many $(\sim 30 \%)$ countries, ancillary tests are required by law and interpreted as confirmatory [9], and it seems hard to give up tests we never really trusted in the first place. Ancillary tests in a clinically declared patient may, inconveniently, show equivocal results in one of five patients; results depend on test used, timing of test, and mechanism of brain death-more often false negative if intracranial pressure is not markedly elevated [10]. Ancillary tests may confuse physicians, lead to more tests, delay closure, and block the usual pathways.

\section{What can we conclude?}

Now, 60 years after the very first descriptions from French neurologists and neurosurgeons and 50 years after the Harvard Criteria, we can look with satisfaction at the accomplishments in brain death determination and know that a well-prepared neurologic evaluation provides the utmost objectivity. Although it should be clear and uncontroversial, physicians still have to counter pervasive myths and contradictions [11]. We should not become alarmed by contentious court cases in the media. Our proper role is to maintain a high level of competency, which requires rigor [12]. The declaration of brain death is a neurologic ascertainment. Ultimately, this is what matters and is the larger message for us to convey.

\section{Compliance with ethical standards \\ Conflicts of interest \\ None. \\ Ethical approval \\ An approval by an ethics committee was not applicable.}

\section{Publisher's Note}

Springer Nature remains neutral with regard to jurisdictional claims in published maps and institutional affiliations.

Received: 16 January 2019 Accepted: 25 January 2019 Published online: 6 February 2019

References

1. Wijdicks EF (2003) The neurologist and Harvard criteria for brain death. Neurology 61:970-976

2. Wijdicks EF, Varelas PN, Gronseth GS, Greer DM, American Academy of $N$ (2010) Evidence-based guideline update: determining brain death in adults: report of the quality standards subcommittee of the American Academy of Neurology. Neurology 74:1911-1918 
3. Webster PA, Markham LE (2018) Never declared brain dead potential organ donors - an additional source of donor organs? Prog Transpl 28:43-48

4. Tawil I, Brown LH, Comfort D et al (2014) Family presence during brain death evaluation: a randomized controlled trial. Crit Care Med 42:934-942

5. Daneshmand A, Rabinstein AA, Wijdicks EFM (2019) The apnea test in brain death determination using oxygen diffusion method remains safe. Neurology. https://doi.org/10.1212/WNL.0000000000006963

6. Bronchard R, Durand L, Legeai C, Cohen J, Guerrini P, Bastien O (2017) Brain-dead donors on extracorporeal membrane oxygenation. Crit Care Med 45:1734-1741

7. Sandroni C, D'Arrigo S, Callaway CW et al (2016) The rate of brain death and organ donation in patients resuscitated from cardiac arrest: a systematic review and meta-analysis. Intensive Care Med 42:1661-1671
8. Kentish-Barnes N, Cohen-Solal Z, Souppart V et al (2019) Being convinced and taking responsibility: a qualitative study of family members' experience of organ donation decision and bereavement after brain death. Crit Care Med. https://doi.org/10.1097/CCM.0000000000003616

9. Wahlster S, Wijdicks EF, Patel PV et al (2015) Brain death declaration: practices and perceptions worldwide. Neurology 84:1870-1879

10. Kramer AH (2015) Ancillary testing in brain death. Semin Neuro 35:125-138

11. Wijdicks EFM (2018) Deliberating death in the summer of 1968. N Engl Med 379:412-415

12. Smith M, Citerio G (2017) Death determined by neurological criteria: the next steps. Intensive Care Med 43:1383-1385 